\title{
Cuadrar el delito. Corrupción institucional y participación de policías en el secuestro en México
}

\author{
Miquel À. Ruiz Torres* y Elena Azaola Garrido**
}

\section{Resumen}

Este trabajo reconstruye las carreras de policías que se encuentran cumpliendo una sentencia por el delito de secuestro en la Penitenciaría de Santa Martha, en la Ciudad de México, desde el punto de vista de su itinerario "interrumpido" dentro de las instituciones policiales mexicanas. Las entrevistas realizadas nos develan una cultura policial que se basa en cuatro pilares que articulan el significado de las relaciones sociales tanto al interior de la institución, como respecto a los ciudadanos: desconfianza, autoritarismo, discrecionalidad y negociación. Estos rasgos nos conducen a identificar el ethos cotidiano y normalizado de una institución que se sustenta a sí misma y ejerce el abuso de poder para su propia perpetuación, aunque para ello sea necesario actuar en contra de algunos de sus elementos a quienes instrumentaliza como víctimas propiciatorias para la opinión pública.

\begin{abstract}
This work reconstructs the careers of policemen that are carrying out a sentence for kidnapping at the penitentiary of Santa Martha in Mexico City from the perspective of their interrupted itinerary as police officers. The interviews reveal a police culture based on four elements that articulate the meaning of social relationships both within the institution and with citizens: distrust, authoritarianism, discretionality and negotiation. These elements allow us to identify the common and normalized ethos of an institution which abuses power to sustain and perpetuate itself, even though if sometimes this implies sacrificing some of its officers as propitiatory victims for the sake of public opinion.
\end{abstract}

Palabras clave: policía, corrupción, prisión, secuestro, cultura policial, relatos de inocencia. Keywords: police, corruption, prison, kidnapping, police culture, tales of innocence.

* Miquel À. Ruiz Torres es doctor en Antropología Social y profesor-investigador de la Facultad de Ciencias Sociales de la Universitat de València, España.

** Elena Azaola Garrido es doctora en Antropología Social, psicoanalista e investigadora del Centro de Investigaciones y Estudios Superiores en Antropología Social (CIESAS), México D.F. 
urante el sexenio del Presidente Felipe Calderón Hinojosa (2006-2012), especialmente después de implantarse la llamada "guerra contra el narcotráfico", ha habido un aumento generalizado de la percepción de inseguridad en México por parte de los ciudadanos, con lo que se ha ahondado la visión del debilitamiento de la capacidad del Estado para controlar el territorio y ejercer su soberanía. Numerosas bandas criminales dedicadas al narcotráfico internacional han puesto en cuestión el monopolio del uso de la fuerza que posee el Estado, además de imponer sus propias reglas de conducta y marcos de lealtad en los contextos locales y regionales..

Sin duda, el tratamiento mediático de un tema como el secuestro en los últimos años es un síntoma de la generalizada percepción de la descomposición de las instituciones del Estado. La extendida presencia del fenómeno en todos los medios de comunicación, incluyendo la edición periodística y literaria (Ortega, 2008; Scherer, 2009; Padgett, 2010), han multiplicado la conformación de imágenes acerca del miedo a la delincuencia (Garland, 2005). Este aumento del seguimiento mediático ha conllevado un impacto creciente del secuestro sobre el imaginario colectivo.

Pero aquellos relatos mediáticos que vinculan el secuestro con los servidores públicos son quizás los que más repercusión tienen en varios sentidos. Cuando los secuestradores son policías, se incide directamente en la intensificación de la desconfianza de los ciudadanos mexicanos hacia las instituciones del Estado, especialmente las de seguridad y procuración de justicia (Consulta Mitofsky, 2004-2010; Brown, Benedict y Wilkinson, 2006; Larose y Maddan, 2009); y los servidores públicos son vistos y representados como coadyuvantes e instigadores del crimen más que como sus perseguidores (Silva, 2003; Suárez, 2005; Naval, 2006).

La generalización de la percepción de inseguridad y del miedo al crimen también ha provocado un aumento en las políticas y los discursos inspirados por lo que los especialistas han denominado "populismo punitivo" (Arteaga, 2004; Pastor, 2005), reflejado en una demanda de "mano dura" y "tolerancia cero" contra la criminalidad (Benítez, 2004). Este enfoque se ha visto impulsado en los últimos años mediante iniciativas legislativas y políticas del gobierno que han promovido el aumento de las penas y la cancelación de beneficios de libertad anticipada para los responsables de delitos como el secuestro. Siendo así, cuando el populismo punitivo recae sobre los propios policías adquiere unas dimensiones particularmente sig- 
nificativas. Por una parte, puede hacer del populismo punitivo un azuzador del abuso policial más que su paliativo, además de limitarla a una estrategia que sirve más a la legitimación institucional frente al problema de la violencia (Arteaga, 2004). Sin embargo, por otra parte, castigar al policía secuestrador puede que tenga la capacidad de convertirse en símbolo del esfuerzo del Estado por recuperar la legitimidad.

La pregunta fundamental que nos hacemos es qué sentido tienen las aprehensiones y condenas que sufren algunos miembros de las corporaciones para la lógica del funcionamiento policial e institucional mexicano, ¿Son estos castigos una mera escenificación con chivos expiatorios? ¿Existe un vínculo entre el abuso de poder que sufrirían los policías en estos casos dentro de la institución y el que ellos ejercen contra la sociedad, por lo que ambos servirían a la reproducción institucional de la corrupción? ¿Podemos establecer un nexo entre el ethos policial que "cuadra" delitos a los criminalizables y los procesos de culpabilización mediante los cuales les son "cuadrados" delitos como el secuestro?

Los relatos que cuentan los ex policías presos sobre ambas formas de "cuadrar delitos" no tienen por qué ser lineales, coherentes, ni corresponder al mismo ámbito de poder. Reconstruyen su itinerario policial desde la posición de la desgracia y la narrativa de la traición, articulando desde tal posición unos "relatos de inocencia" (Ruiz y Azaola, 2012) sobre su propia trayectoria y su supuesta participación delictiva. No obstante, a pesar de estas fracturas en las narrativas, creemos que en la transición de pasar de victimario a víctima existe, al menos parcialmente, una misma lógica del abuso de poder basada en rasgos que se constituyen como estructurales en la institución, y que proyecta continuidades.

En este artículo, mediante el análisis de las narrativas de los itinerarios interrumpidos que conducen a los policías hacia el encierro carcelario, localizaremos los principales rasgos del funcionamiento policial con respecto a las prácticas de abuso y corrupción. Posteriormente, la pregunta que nos haremos es si dicha "caída en desgracia", que hace que unos pocos policías sean condenados al ostracismo, la exclusión y la subordinación que hallarán en la cárcel, se reduce a actos accidentales o epifenómenos o, si no es así, qué lugar ocupa para la estabilidad y reproducción de las instituciones policiales mexicanas. 
Esta investigación está basada en entrevistas etnográficas llevadas a cabo a finales de 2008 a un total de treinta y cinco reclusos varones ${ }^{1}$. Estos presos habían pertenecido a alguna institución policial y se encontraban cumpliendo una sentencia por secuestro en la penitenciaría de Santa Martha Acatitla, en la Ciudad de México. Ellos representaban 14\% del total de las doscientas cincuenta y nueve personas sentenciadas por este delito en dicha penitenciara, y constituían el total de los policías presos por secuestro en esta prisión. La edad promedio en la que fueron detenidos fue de 30.6 años, mientras que la sentencia media que estaban cumpliendo era de 31.2 años, con un mínimo de doce y un máximo de noventa años. El 33\% de los entrevistados perteneció a la Policía Judicial del Distrito Federal, 32\% a la Policía Preventiva de la misma entidad, y 26\% a la Policía Judicial Federal o a la Agencia Federal de Investigación. De todos ellos, 72\% eran originarios del Distrito Federal mientras que 28\% había nacido en diferentes Estados de la República Mexicana.

El análisis de las entrevistas no se llevará a cabo mediante la exposición de biografías individualizadas, los relatos han sido desmenuzados en un análisis estructural con la intención de reconstruir el itinerario de los sujetos al interior del marco institucional policial. Aquí, la relación biográfica cobra sentido dentro de la institucionalización de las conductas. Nuestra intención es registrar de qué manera las historias personales son legibles e inteligibles dentro del contexto grupal e institucional, tanto formal como informal. De este modo, hemos agrupado los ejes temáticos para crear una secuencia colectiva que va, desde que los policías ingresan a la academia, hasta que son aprehendidos, juzgados y encarcelados.

\section{Análisis}

La lealtad: aprendiendo códigos, valores y reglas

Los reclutas llegan a la academia de policía con un conjunto inestable de creencias acerca del papel de la institución policial y de su vocación de servicio público. Estos valores, aprendidos de los lugares comunes que circulan en su comunidad así como de los estereotipos de la cultura mediática

1 Las entrevistas aparecen codificadas en el texto desde la E1 a la E35. 
y del currículum educativo formal, no perduran más allá de los primeros días de contacto con la educación informal institucional, transmitida por los policías veteranos a los novatos en los rondines. Este carácter volátil y efímero de los valores de los novatos también ha sido descrito en otras investigaciones (Ford, 2003) que han analizado los "relatos de guerra", o historias de veteranos, como factores de socialización informal de los reclutas en la subcultura policial, los cuales son capaces de "desacreditar" aquellos valores y de hacer ver como irrelevante el entrenamiento formal (Ford, 2003: 88; Azaola y Ruiz, 2009; 2010).

A medida que avanza el proceso de socialización informal, el conjunto de creencias precarias y poco arraigadas acerca del papel de los policías en la sociedad cede ante un sistema de lealtades a sus compañeros y de obediencia a sus jefes, para lo cual se requiere un proceso de aprendizaje de los valores y normas propios de los grupos o clanes de implantación local y cercana (Azaola y Ruiz, 2009; 2010). Por ejemplo, un sentenciado a 52 años relata con detalle su particular proceso de incorporación al ethos del grupo a partir de experiencias propiciatorias de reajuste moral:

Poco a poco, el mismo medio lo va cambiando a uno. Vi cosas que nunca hubiera visto: accidentes, violaciones, agresión: el uniforme es símbolo de agresión. Cuando te ven con tu uniforme, te mientan la madre, te avientan piedras porque poco a poco se ha ido deformando la imagen. Al principio no, pero luego vas siendo testigo de las cosas que van pasando y va cambiando uno, y si eras pasivo, te haces agresivo para poderte defender. Porque primero yo les decía, tenga la bondad de enseñarme una identificación, pero hasta que una persona me puso una pistola, cambió mi mentalidad. Lo logré convencer de bajar su arma y con detalles de esos uno empieza a perder la confianza en la sociedad y es recíproco, también la sociedad desconfía del servidor público (E10).

Identificamos en este proceso de aprendizaje cuatro fenómenos interdependientes: a) la obediencia al mando y sus requerimientos discrecionales y arbitrarios, b) la adopción de un horizonte de lealtades hacia el grupo informal o clan, c) la adaptación al ejercicio del abuso de poder y el goce de sus beneficios y d) el encapsulamiento defensivo frente a una sociedad que rechaza, agrede a los policías, y que claramente, los ve como enemigos.

Hay que tener en cuenta que, aunque es necesaria una sumisión a la jerarquía, la obediencia no se genera solamente por acatamiento disciplinario (a), sino también por el establecimiento de un acuerdo implícito de reciprocidad (b y c). Según éste, se inicia una relación de lealtad cuando 
los mandos ordenan actos ilegales a los agentes de su clan (su "núcleo"), pero haciéndoselos ver como dones o regalos:

Los subordinados no denuncian al jefe porque hay un acuerdo, un amarre: te voy a dar la oportunidad de que ganes una lana extra, pero vas a formar parte de mi núcleo. Como es una oportunidad, difícilmente la rechazan. Cualquier policía está tentado pues una persona buena no sirve para ese trabajo. Desde que entra, le dicen: te vas a ganar una lana pero tienes que hacer cosas malas y el que entra, le entra, y el que no, lo sacan, lo mandan para otro lado porque no sirve (E10).

En otras palabras, el sometimiento a la jerarquía es necesario para la consolidación de un grupo policial informal; pero para que sea realmente eficaz, el clan debe permitir la realización de actividades ilegales que vinculen a unos miembros con otros en relaciones de dependencia mutua tales que los obliguen a la lealtad mediante códigos de silencio - algo que ha sido detectado en la literatura y conocido como "blue codes" (Skolnick, 2002; Benoit y Dubra, 2004; Trostle, 2005; Westmarland, 2005). Una dinámica propia de esta obediencia es el acatamiento de órdenes que no son de acuerdo a derecho ni se llevan a cabo dentro de procedimientos legales. Un reo sentenciado a veintiocho años nos cuenta: "Yo estaba de guardia y es común que lleguen a la oficina y te digan: ve a tal cosa, y eso fue lo que pasó. Yo no traía ni un oficio de ir a buscar a esas personas pero resultó que hubo varios muertos y fue por eso que estoy en este lugar" (E16).

Este acatamiento obediente se entiende como una conducta iniciática que entabla derechos y obligaciones y que inaugura la inmersión en el código de silencio. Se trata de un involucramiento criminal que, al generar indefensión en los policías, también promueve la lealtad hacia mandos y compañeros, pues la indefensión es exigida por la gramática del código para garantizar la impunidad. Así, la adaptación y aceptación del abuso de autoridad por parte de los neófitos es un ingrediente básico del aprendizaje de la cultura policial, ya que con el goce de los beneficios obtenidos ilegalmente se va conformando la lealtad de los miembros del clan en un entorno peligroso e inestable.

Con respecto a la obediencia a la jerarquía, es importante remarcar que la jerarquía de mando, conformada de acuerdo al rango formal, no necesariamente coincide con la jerarquía de estatus, configurada como la distribución diferencial del prestigio, que suele ser de carácter informal y que también se combina con las jerarquías formadas con base en la habilidad y antigüedad de sus miembros (King, 2005: 101). En nuestro caso, esto signi- 
fica que la obediencia a los jefes de los grupos o clanes informales que se organizan para cometer delitos, no necesariamente ha de dirigirse hacia los mandos formales, así como tampoco el hecho de tener mando ha de implicar conducir uno de dichos clanes. Es evidente que tales diferencias entre poder formal e informal puedan conllevar choques o conflictos de intereses; aunque, no obstante, siempre se ha de contar con algún reconocimiento de autoridad formal o de estatus informal para poder controlar la logística delincuencial del grupo informal.

\section{La habilidad: administrando la información y la experiencia}

Para el caso de los presos entrevistados en este estudio, las habilidades adquiridas como policías (destrezas técnicas, métodos delictivos y experiencia en la calle, así como redes sociales y obtención de información sobre las víctimas) fueron utilizadas principalmente con el fin de organizar, planificar y ejecutar secuestros. En este sentido, la puesta en práctica del acto delictivo de privar a una persona de su libertad y exigir un rescate (o una confesión) por su liberación e integridad física, cabe considerarla hasta cierto punto como una estrategia más para la obtención de recursos en un contexto de oportunidades (Naylor, 2003). Esta estrategia debe ser situada entre otras prácticas que también son llevadas a cabo (soborno, extorsión) utilizando la coartada de la autoridad legal y el monopolio de la violencia otorgados por el Estado.

El trabajo policial suele acarrear el contacto estrecho con el crimen organizado, aunque la finalidad de dicho vínculo vaya dirigida a combatir y prevenir el propio crimen. Sin embargo, la especificidad que hemos encontrado es que el establecimiento de dichos contactos con fines de actividad criminal llega a ser constitutivo y no accidental en el quehacer de las policías mexicanas. Así, puede llegar el caso de que las diferentes corporaciones se repartan los territorios más propicios para cada uno de los delitos, codo a codo con delincuentes que no son policías:

Yo podía tener contacto con policías que se dedican a robar en las noches, a trabajar con las sexo servidoras y entre ellos mismos se organizan: venta de drogas, delitos organizados, robos a negocio, a casa habitación, a instituciones, y esto viene de muchos años por la forma de convivencia que se da en la corporación; te mandan a una Delegación y a otra y empiezas a conocer a más gente. Cada lugar tiene su tipo de delito (E10). 
Las alianzas estratégicas entre policías y civiles delincuentes pueden ser tan diáfanas como en el caso siguiente. Nótese cómo el entrevistado vincula los conocimientos adquiridos como policía (dando a entender abusos de autoridad) con su colaboración en el secuestro:

Yo aprendí a conocer todos los modus operandis de la Policía, de los delincuentes comunes, yo le di el mejor uso a ello porque capturé a los mejores, a los que yo quise. Me enseñaron a investigar, a tener calma en una investigación para poder llegar a su fin, y eso me llevó a tener a los delincuentes en mis manos y a que me platicaran cómo hacían las cosas. A algunos los metí a la cárcel, a otros no, porque no eran tan malos: yo decidía a quién sí, y a quién no (E14).

Uno de los principales recursos con el que cuentan los policías a la hora de planificar un secuestro es el conocimiento de las relaciones sociales, de los hábitos de comportamiento y de los espacios frecuentados por sus víctimas. Se trata de utilizar la información adquirida desde la posición de poder que les otorga la institución. Así, es frecuente que los secuestradores, o bien procedan directamente del entorno inmediato (empleados domésticos, guardaespaldas, así como amigos e incluso parejas y familiares), o bien hayan recabado información entre éste.

En general, basta con controlar ciertos espacios públicos para localizar a ciertos actores y delimitar ciertas actividades susceptibles de ser explotadas; se trata de identificar vulnerabilidades en la población con el fin de aplicar el abuso de poder. Aunque para que sea viable, los policías deben secuestrar personas lo suficientemente comprometidas con el delito para poder ser extorsionadas, y lo suficientemente poderosas para poder obtener un beneficio de ellos. Como en el caso que sigue, son especialmente atractivas las situaciones donde las propias víctimas son sorprendidas llevando a cabo actos ilegales o inmorales, ya que las posibilidades de extorsión aumentan:

Posteriormente, fui perfeccionándome y especializándome en trabajar a los pedófilos y homosexuales que andan circulando y buscando a los niños que se prostituyen allí en la Zona Rosa. Y veíamos al niño que lo subían al auto y nosotros los bajábamos de los autos y amenazábamos a los pedófilos con presentarlos ante el Ministerio Público y les decíamos que los íbamos a sacar en el periódico y como eran puros doctores, licenciados, puros profesionistas, (...) les mostrábamos el Código, que por tener comercio carnal en vía pública... y entonces ya los extorsionábamos con 50 mil pesos que para el Ministerio Público, para Gobernación, etc. (E18). 
Según vemos en este ejemplo, la captación de individuos criminalizables con fines de extorsión o secuestro, resulta mucho más segura si se usan los espacios y tiempos propicios para el abuso, aquellos donde los policías se encuentran más legitimados para ejercer la violencia arbitraria. Al respecto, es bien conocido por la literatura que los conflictos entre policías y ciudadanos son exacerbados durante la noche, donde surgen grupos sociales de resistencia (Phillips y Smith, 2000: 490). Asimismo, el hecho de sufrir un arresto durante la noche y en espacios conocidos como peligrosos, incrementa la posibilidad de que los agentes apliquen formas de fuerza más severas (Crawford y Burns, 2008: 332) pues se sienten legitimados por la metodología de la sospecha que aplican. Por tanto, bajo ciertas condiciones propicias espacio-temporales, y la selección de ciertos individuos criminalizables, es como los agentes policiales llevan a cabo sus "cacerías" de la forma más operativa y minimizando sus riesgos.

\section{El negocio: aprovechando el poder otorgado por el Estado}

Una vez en posesión de los conocimientos y las habilidades necesarias, la ley, es decir, la coartada de la ley y toda la simbología institucional (uniformes, jerga legal, autos, placas, armas), además de los espacios de poder generados en la aplicación arbitraria e interesada de la autoridad; todo ello es utilizado por los policías con la finalidad principal de extorsionar a la población para beneficio económico o para la búsqueda de estatus dentro de la institución.

Otros autores ya han identificado, mediante la metodología etnográfica, cómo la corrupción policial es la norma mientras que las conductas honestas son consideradas como conductas desviadas (Arteaga y López, 2000). Cómo la policía se convierte en una agencia habilitada para regular actividades delictivas (Stanley, 2004; Saín, 2008), o cómo la cultura policial tiene una doble adscripción institucional, la legal y la ilegal (Suárez, 2005). Se trata de la máxima acerca de la corrupción según la cual todos los espacios públicos son puestos al servicio de intereses particulares. O en términos de aforismo: vicios públicos, virtudes privadas (Lomnitz, 2000).

Pero en nuestro caso, volvemos a llamar la atención sobre el nivel de sistematización y aceptación de las prácticas basadas en esta lógica. Es como si el cuidado del negocio particular dejara de estar limitado a una "virtud" privada para extenderse a la propia percepción y expectativa de lo público e institucional, donde los intereses particulares se solapan e intercalan dentro de intereses grupales que pueden ir de los propios grupos 
informales hasta la misma institución en su conjunto; lo cual incluye las condiciones mínimas para su funcionamiento. En otras palabras, pareciera como si la única forma en que el sistema institucional mexicano puede funcionar como tal (como estructura organizada colectivamente), fuera mediante la dedicación de sus trabajadores a la defensa de intereses privados o grupales informales que están en su interior o en relación con él.

Veamos algunos ejemplos. Según este ex Policía Judicial de 38 años, los jefes policiales se rodean dentro de la institución de una especie de séquito, no solamente para su atención personal, sino para desarrollar sus intereses económicos privados:

Todos los jefes tienen sus ayudantes técnicos, pero es para su servicio personal, y pueden tener de uno hasta seis y les dicen "perros", ellos no investigan, hacen su negocio personal, que puede ser lícito o ilícito. También tienen unidades propias de patrullaje, y son los que se quedan con los vales de gasolina, con los cartuchos; al resto no le dan ni para practicar (E6).

En este otro ejemplo, el sujeto nos relata la rutina de sobornos interinstitucionales y extorsiones extra institucionales en la que se convierte el funcionamiento policial cotidiano, basado también en el reparto de territorios. Insistimos en el carácter de don que adquiere la relación entre los clanes y los jefes formales que dan cobertura a las prácticas; así, es necesario pagar ciertas cantidades o hacer regalos de manera constante y aparentemente voluntaria, a fin de actualizar los acuerdos:

Nos pedían dinero que teníamos que dar para las patrullas, eran mil pesos que teníamos que dar a los comandantes, no importaba si trabajamos o si no. Teníamos todos los cabarets de la colonia Doctores, de la Guerrero, puras colonias con alto índice delictivo por lo que siempre había dinero. (...) Teníamos que dar mil cada semana y aparte teníamos que darle discos o una botella de Martell o un arma; cada mes nos pedía eso (E18).

Para percibir mejor la importancia del carácter estructural de las prácticas de corrupción y abuso, consideremos otro ejemplo. Según el relato de un ex Policía Judicial sentenciado a cincuenta y dos años, da la impresión de que actuar según los procedimientos legales establecidos, fuera una decisión activa que los policías sólo pudieran tomar realizando un notable esfuerzo personal: 
A esos sujetos los agarramos con droga (...) y los subimos a la patrulla. Nos ofrecieron dinero y la ambición me ganó. (...) Fue una mala decisión que tomé. El medio nos gana, quiere uno dinero fácil. (...) Dentro de la policía es una tentación que se vive a diario, pero depende de uno, uno puede decir que no y presentar a los detenidos ante el Ministerio Público (E18).

\section{El pleito: confrontando jefes y clanes}

De acuerdo con las narrativas que construyen los ex agentes, de la misma manera que los policías seleccionan individuos criminalizables entre la población, dentro de la institución también se dan caídas en desgracia de agentes considerados sacrificables. Cuando los policías que ejercen el abuso de poder son acusados y en algunos casos sentenciados, parece ser que ello no está en función de un mayor celo en aplicar los controles internos anticorrupción o en una verificación externa y efectiva del quehacer policial. Su aprehensión aparece en los relatos como debida a un cuestionamiento de su posición dentro de los grupos informales. Una vez desatado el conflicto con la jerarquía, los agentes acusados proyectan sobre sus jefes las mismas acusaciones de abuso de poder que sufren: "yo cometí tres delitos, de éste por el que vengo, fue porque tuve broncas con el comandante con el que trabajaba y quien nos involucraba, yo estuve cometiendo fechorías y tuve problemas con él y por eso nos involucraron en este delito" (E2). El mismo ex judicial, condenado a dieciséis años, relata cómo un desacuerdo sobre los beneficios obtenidos en sus actividades ilícitas desencadenó la hostilidad de su mando: " comencé a tener problemas con el comandante porque él nos robaba. Entonces discutimos y (...) y fue la manera como me cuadraron ese tipo de delito [secuestro], por medio de ese comandante" (E2).

Uno de los factores que pueden precipitar la caída en desgracia es el conocimiento de información comprometedora; en otras palabras, el haber sido personal de confianza de los jefes. En otras ocasiones, la acusación es consecuencia de haber dirigido algún operativo, por ingenuidad, desconocimiento o por una celada, contra personas que cuentan con protección en la institución. Como la mayoría de estos operativos se ordenan sin seguir los procedimientos formales de detención, cualquier agente está expuesto a ser acusado si da un mal paso.

Un día detuvimos a un señor en La Condesa pero resultó que era Gerente General de Televisa y de otra empresa, y se les encontró cocaína, 1 kilogramo, y nos ofrecieron 100 mil pesos a cada uno para que no los detuviéramos pero, 
cuando estábamos esperando el dinero, llegaron a detenernos, y nos acusaron por secuestro (E18).

Como vemos, el Código Penal se logra aplicar contra los policías abusadores siempre y cuando la víctima tenga recursos para defenderse.

Es interesante observar cómo de acuerdo a los relatos, las acusaciones se van sumando y restando según el interés en neutralizar a un rival, y según la capacidad de éste para desprenderse de los cargos. Es decir, el Código Penal es concebido como arma estratégica de modo discrecional por cada una de las partes. No obstante, las jerarquías formales marcan fuertemente la capacidad de defensa de los acusados, hasta el punto en que las narrativas de desgracia perciben como suicida un posible contraataque: “a lo mejor está bien [estar aquí] porque, de otro modo, yo les iba a hacer una broncota a los de la Procuraduría al decirles: ustedes me han acusado pero ustedes están en extorsión, en droga... allí no puedes denunciar y, si denuncias, te mueres" (E16).

En casos donde diferentes mandos tienen un conflicto de intereses, la resolución del mismo puede ser muy agresiva. Se trata de una competencia por recursos materiales, simbólicos y de estatus donde el sometimiento del contrincante es necesario para defender la posición de poder (formal e informal) frente a sus subordinados, lo cual incluye, por supuesto, la neutralización. En el siguiente ejemplo, un mando veterano construye un relato donde fue acusado por su jefe inmediato por no acatar una orden (arbitraria) de liberar a un detenido influyente:

A mí me mandaron a ejecutar una orden de aprehensión pero la persona que detuve (...) era amigo del jefe de la Policía. El detenido traía un celular y se comunicó con [él] y (...) y me ordenó que lo dejara ir (...) Tenía orden de aprehensión girada por un juez, por fraude, y me negué a soltarlo y lo metí al Reclusorio Sur. Mi jefe (...) me dijo que me iba a chingar y yo le dije que no me asustaba y me dijo: "vas a ver si no te lo cuadro...". Pasó el tiempo y (...) llegaron a mi casa, por órdenes de arriba, y (...) al ver que torturan a mi hijo, tuve que aceptar. Nos hicieron firmar después de 5 días de tormento (E31).

Es fundamental captar la dimensión simbólica de abuso de poder que adquiere la fórmula "cuadrar un delito" cuando es usado como argumento de coacción en las narrativas sobre los conflictos entre policías; y cómo se concibe un uso instrumental del Código Penal, así como de los órganos de control interno en función de intereses particulares o grupales. 
Sin embargo, no necesariamente aparece un pleito con algún mando o entre corporaciones. En ocasiones, a pesar de que los policías cumplen con todo lo que se les exige, incluyendo actos claramente inmorales e ilegales que denotan altos grados de obediencia y lealtad, si la operación falla, son los agentes de más baja gradación quienes deberán expiar la culpa del conjunto.

En definitiva, según los relatos, los policías aprenden primero, y luego aplican y exhiben la regla de conducta informal que rige el clan. Pero si dicha regla se sobreexplota en exceso, se infringe o se ignora, entonces "los saberes de los que se cree portador y guían su actuación son redireccionados en su contra" (Suárez, 2005: 101).

\section{El problema: cuadrándole a uno el delito}

Y llega la detención. Los delitos de los que son acusados los policías son percibidos y construidos en sus narrativas como que les han sido "cuadrados"; es decir, inventados ad hoc y expresamente seleccionados y ajustados para que los acusados puedan ser sentenciados por el sistema de justicia. "Cuadrarle" el delito es, desde su posición de caídos en desgracia, aplicar el Código Penal a un policía de manera discrecional y "a la medida", como parte de los reajustes de las relaciones de poder que se dan al interior de la institución policial y frente a los requerimientos externos:

Yo creo que en el dormitorio 5 alrededor de un $50 \%$ son inocentes del delito de secuestro. Casi todos los compañeros servidores públicos cayeron por extorsión o porque andaban robando, o por la rivalidad que hay entre corporaciones que hace que les busquen cuadrar el secuestro por la presión de la sociedad y para que vean que ellos sí están dando resultados (E19).

La estrategia más habitual que aparece para coaccionar a los policías y que acepten que se les "cuadre" el delito es la amenaza contra su vida o la de sus familiares: "Al no poder desaparecerme por el acta que levantó mi familia, por eso me tuvieron que cuadrar el delito porque la víctima no me reconocía y lo cuadraron por tiempo y modo. A mí me decían que iban a dañar a mi familia y por eso firmé" (E5). Según afirman, esta coacción se lleva a cabo al mismo tiempo que se recurre a la tortura, especialmente si se presentan resistencias para aceptar la firma de las declaraciones autoinculpatorias previamente elaboradas. 
No habría que olvidar que la coacción para "cuadrar" un delito no implica que los policías afectados no hayan cometido ninguna ilegalidad. Más bien, cuadrar un delito conlleva un uso discrecional de la ley y un procesamiento arbitrario y contrario al debido proceso; por lo que la disonancia entre acusación y delito sería un rasgo fundamental de esta aplicación de la justicia. En algunos casos, incluso se describe cómo es posible "fabricar" los cargos desde cero: conseguir autoinculpaciones, cuando en un inicio no existe cargo alguno en su contra y ni siquiera se ha abierto una averiguación previa.

Una vez que ya han sido sentenciados y están cumpliendo una condena, la amenaza de volver a "cuadrar" el delito es asumida por el reo para toda su vida, tanto dentro de la cárcel como cuando ya hayan sido excarcelados: "y si saliera, pues me iría a otro lado, porque aquí luego sale uno $\mathrm{y}$ te vuelven a cuadrar el delito porque ya te tienen fichado" (E33).

En sus relatos de inocencia los ex policías entrevistados parecen percibir con más claridad que se ha cometido una arbitrariedad contra ellos, precisamente porque la lógica de la arbitrariedad de las sentencias que sufren es análoga e inteligible, la misma que ellos ejercieron cuando eran policías; es decir, cuando detenían a personas pasando por alto los procedimientos y garantías:

Aquí también hay gente inocente, quizás un 50\%, pues por la carga de trabajo que teníamos, íbamos por gente para justificar que había trabajo y agarrábamos a los drogadictos y así justificábamos que estábamos trabajando. Hacíamos informes pero no eran ciertos: que fuimos a tal lado, que no encontramos a la persona, pero no era cierto, era nomás para justificar que se había investigado (E30).

\section{Discusión y conclusiones}

Existe en otros países la creencia compartida entre los mismos policías, de que el trabajo policial sería totalmente inefectivo si los agentes no fueran lo suficientemente deshonestos para llevar a cabo ciertos actos de corrupción, como la creación de informes falsos o el sembrar pruebas (Goldschmidt, 2008:130). En el caso del secuestro a cambio de rescate es sintomático que no haya ninguna ideología que pueda justificarlo como bien colectivo, no obstante, su presencia en las corporaciones policiales nos indica que el abuso contra los ciudadanos podría ser una característica estructural de cómo actúan las instituciones del Estado. Pero, ¿qué estamos entendiendo 
por estructural? ¿Qué vínculos puede haber entre las prácticas de abuso que se describen en las diferentes narrativas y la continuidad institucional?

A lo largo de este texto, hemos reconstruido con base en los relatos de los entrevistados, las carreras policiales de los reclusos desde la imagen de un itinerario interrumpido que los ha llevado a la situación de sentenciados por secuestro. En tal reconstrucción hemos identificado cuatro fenómenos implicados que otorgan sentido a los procesos de aprehensión y que nos hablan de cierta lógica práctica (Bourdieu, 2002) del funcionamiento policial:

a) La selección arbitraria entre individuos criminalizables, en este caso los mismos policías, cuya dinámica es inteligible en el marco de las que realizan los agentes contra los ciudadanos al recabar a las personas que han de pasar por el sistema de justicia. Los policías presos habrían sido víctimas de la misma lógica que ellos han aplicado. El principal criterio de selección es extrajudicial y está originado en rivalidades y ajustes de cuentas intrainstitucionales.

b) El uso instrumental, parcial e interesado del Código Penal ("cuadrar" un delito) como estrategia para cancelar la capacidad de acción de elementos cuyo quehacer se ha vuelto problemático. En este sentido, se llegaría a sentenciar a los acusados aún sin pruebas, hasta el punto de que el despliegue legal es una mera escenificación sin contenido, una punibilidad performativa de una eficacia extralegal.

c) La condena como castigo institucionalizado aplicado sobre conductas supuestamente ilegales, instaurada como recordatorio de la lealtad debida a los acuerdos y clanes locales y exigida incluso en condiciones de encierro carcelario. Se trataría de "cancelar" a aquellos policías que dejarían de estar suficientemente sujetos al horizonte de obligaciones y reciprocidades del clan, y reventarían las reglas mediante las cuales se garantiza la pervivencia de prácticas de obtención de recursos.

d) Las aprehensiones de tales individuos como respuesta al requerimiento que diversas instancias políticas, mediáticas y sociales hacen para un mayor control y persecución del abuso de poder ejercido desde las corporaciones policiales. Tales detenciones no son sistemáticas ni efectivas, sino que solamente operarían como catalizadores simbólicos de acuerdos de legitimidad institucional. 
Los rasgos peculiares que emergen a través de las situaciones críticas de detención que nos han sido relatadas, nos conducen al siguiente punto: el quehacer normalizado de las instituciones policiales en México, es concebido por sus agentes principalmente para sustentarse a sí mismas; mientras que sus miembros, organizados en grupos informales, ejercerían el abuso de poder para la propia perpetuación y progreso de sus "carreras" al garantizar la optimización de recursos obtenidos mediante actos criminales, tales como el secuestro, la extorsión o la detención ilegal. Es en este contexto que como el abuso de poder es banalizado y normalizado por sus ejecutores en sus narrativas, hasta el punto de convertirlo en un lenguaje de supuestos compartidos incluso con la población que sufre estos abusos.

Tales rasgos que surgen de los itinerarios personales hacia el encarcelamiento, nos describen la práctica institucional policial permeada por relaciones de poder abusivas que parecen constitutivas de la continuidad institucional. Sin embargo, ¿en qué características propias de la llamada cultura policial podemos fundamentar dicho carácter estructural?

a) En primer lugar, la desconfianza, algo ya identificado como idiosincrático de las sociedades policiales en diversos países (Skolnick, 2002; Saín, 2008; Kutnjak y O'Connor, 2010) y en México (Suárez, 2005; Davis, 2006; Naval, 2006; López, 2007; Azaola y Ruiz, 2009, 2010). La desconfianza predomina tanto al interior de la institución como en las relaciones entre policías y ciudadanos. Ésta coadyuva en la hostilidad mutua que sienten unos con otros. La desconfianza interna, generalizada e intensificada por los códigos de silencio, suscita relaciones laborales atravesadas por la suspicacia y la prudencia, y en las que cualquier acción puede ser contraproducente, por lo que se potencian la ineficiencia y la parálisis institucional.

b) En segundo lugar, el autoritarismo, un rasgo entendido como obediencia, aunque desleal, una conformidad basada en un tipo de sumisión a la autoridad nunca aceptada dado que los mandos son percibidos como carentes de legitimidad para ocupar sus cargos aunque es una percepción que proviene de relatos de traición. Este autoritarismo favorece las conductas disimuladoras y los engaños sobre un fondo de desconfianza, un juego de apariencias mientras las cosas van de cara, pero que puede desembocar en traiciones, humillaciones, persecuciones y castigos en cuanto un agente cae en desgracia dado el carácter eminentemente jerárquico, desigual y discriminatorio de las relaciones internas. Este tipo de lealtad 
forzada cristaliza mediante actos de reciprocidad infame basada en conductas ilegales, las cuales conducen a la indefensión y la vulnerabilidad de los subalternos y la impunidad y el abuso de los dominantes. La baja legitimidad de todo el sistema de autoridad ahuyenta a los policías de actuar hacia el bien común y los anima hacia el interés particular y a sacar provecho mientras haya oportunidad.

c) En tercer lugar, la discrecionalidad, la cual se enraíza en el uso parcial e interesado del Código Penal (y de todos los atributos simbólicos de la autoridad) como arma estratégica para la obtención de recursos. Esta capacidad de individuos y grupos informales de actuar por su cuenta en defensa de sus intereses, genera un clima de imprevisibilidad y arbitrariedad donde cualquier coartada de legalidad puede ser usada como argumento de coacción para la negociación, lo que hemos definido como "paralegalidad".

d) Por último, la capacidad de negociación. A pesar de que nuestro trabajo secentra en carreras policiales interrumpidas, ellono deja de ser excepcional, ya que predominan los acuerdos de reciprocidad (tanto entre iguales como entre jerarquizados) sobre la ruptura con las reglas informales. Hay que entender que la negociación se realiza sobre intereses privados y entre actores locales, por lo que no se considera a la ley como una garantía abstracta general, sino como argumento de poder para las relaciones informales o como techo máximo para la negociación. Existe un alto grado de flexibilidad para llegar a acuerdos ventajosos, ya sea adaptando la norma legal o pasando por encima de ella. La suma de los anteriores rasgos más la capacidad de negociación nos da un contexto institucional donde se normalizan unas prácticas corruptas que utilizan la legalidad como coartada para abusos de poder tales como el secuestro.

Es importante captar la dimensión central que ocupa la legitimidad institucional en la precipitación de prácticas abusivas. Según lo que se ha dicho al respecto del logro de la conformidad-compliance- dentro de las instituciones (Wilson, 1992), la eficiencia de éstas depende de cómo es percibida por sus miembros la legitimidad de los acuerdos que establecen las reglas de su funcionamiento en cuestiones tales como roles jerárquicos o tratamiento de la desviación. Esto hace que dichas reglas deban estar "enraizadas dentro de un marco de ideas compartidas con respecto a me- 
tas, estatus y premios" (Wilson, 1992: 17). Según puede desprenderse de nuestro análisis, las instituciones policiales mexicanas están atravesadas por dos procesos que socavan su legitimidad a ojos de sus propios trabajadores, y que reorientan su eficiencia hacia metas no formales: su instrumentalización para objetivos particulares ajenos al bien común, y su nivel de intervención externa y ajena a sus propósitos explícitos. La conformidad al interior de la institución policial se lograría, entonces, en el contexto de un autoritarismo suspicaz que obliga a negociar discrecionalmente para beneficiar en algún momento a todos sus miembros.

Así, metas, estatus y premios informales y frecuentemente ilegales, son establecidos por clanes y jerarquías, de una manera no centralizada y desde un concepto parcial, local y relativo de justicia, y se dirigen a la obtención de recursos materiales y simbólicos mediante el abuso de poder. En pocas palabras, la conformidad se consolida precisamente gracias a la desviación sistemática de los objetivos formales, mientras que las ideas compartidas se basan en que la eficiencia que hay que garantizar es la del logro de ganancias particulares.

Las instituciones policiales son percibidas como ilegítimas por sus miembros (así como por los ciudadanos) y esto incluye su estructura de mando y su modo de operar. Pero aún así, se les otorga conformidad siempre y cuando posibiliten la obtención de recursos por métodos abusivos y en un contexto de impunidad. Este funcionamiento basado en el abuso de autoridad se convierte, gracias al uso ventajoso de la coartada legal, en estructural y constitutivo. Es por ello que perviven dichas prácticas corruptas incluso a pesar de las periódicas "limpiezas" a las que son sometidas algunas de las corporaciones, ya que el efecto de poder que se deriva de la apropiación parcial y particular de la fuerza de la ley, permanece.

Entonces, ¿qué efecto tiene el encarcelamiento de algunos policías para las estructuras informales de poder que rigen al interior de la institución y para fructíferas prácticas tales como el secuestro? Dichas neutralizaciones ¿son funcionales a la reproducción institucional o meros epifenómenos?

Entendemos que el castigo es bastante arbitrario e imprevisible. Según hemos visto, desde la perspectiva de la posición de desgracia, no se puede saber con certeza si uno está rompiendo las reglas demasiado como para ser sancionado, o si lo será aunque no se hayan roto. Incluso cumpliendo con todo lo prescrito por las reglas informales, tal y como aparece en los relatos, los policías son igualmente encarcelados mediante la participación del factor traición. Por lo que deducimos que el confinamiento no puede desempeñar un papel de regulador eficaz de la conducta policial apropiada para las estructuras informales y las prácticas corruptas. 
No obstante, aunque los policías encarcelados por secuestro no dejan de ser una anomalía, dicho castigo sí puede representar un papel hacia el interior y el exterior de la institución, estableciéndose alguna continuidad entre las dos formas de "cuadrar". Por una parte, recuerda la importancia de sujetarse a las reglas informales que rigen, no como un castigo sistemático hacia aquellos que las subvierten, ya que la mayoría parecen quedar impunes, sino como una amenaza de violencia arbitraria e indiscriminada que puede caer sobre cualquiera. Esto actuaría como recordatorio de que no se puede estar dentro sin participar de los goces del abuso de autoridad y de que es obligatorio llegar a acuerdos de reciprocidad infame y de impunidad compartida para beneficiarse de la coartada de la ley. El conglomerado de ideas acerca del cometido policial que siguen esgrimiendo los policías presos, nos recuerda cómo su comportamiento en tal situación crítica sigue enraizado en un modelo discrecional y local de justicia y en una percepción de muy baja legitimidad institucional (Douglas, 1996: 176).

Finalmente, los policías entre rejas también serían íconos con mucha fuerza expresiva, víctimas propiciatorias para la opinión pública sobre las cuales actores centrales del Estado escenifican una reinvención de su propia legitimidad, personajes de una trama orquestada para otorgar precarias prórrogas de conformidad social a unas instituciones que son percibidas como construidas contra y a pesar de los ciudadanos.

\section{Bibliografía}

Arellano, Efrén, 2009, Secuestro. Actualización del Marco Jurídico, México, Centro de Estudios Sociales y de Opinión Pública, Documento de Trabajo núm. 64.

Arteaga Botello, Nelson y Adrián López Rivera, 2000, “Everything in this Job is Money': Inside the Mexican Police", World Policy Journal, Otoño, pp. 61-70.

Azaola Garrido, Elena y Miquel À. Ruiz Torres, 2010, "Papeles policiales: abuso de poder y eufemismo punitivo entre la Policía Judicial de la ciudad de México", Desacatos, núm. 33, pp. 95-110.

Azaola Garrido, Elena y Miquel À. Ruiz Torres, 2009, Investigadores de papel: poder y derechos humanos entre la Policía Judicial del Distrito Federal, México, Fontamara.

Benítez Manaut, Raúl, 2004, “México: seguridad ciudadana, conflictos y orden público", Nueva Sociedad, núm. 191, pp. 103-116. 
Benoit, Jean-Pierre, y Juan Dubra, 2004, "Why do good cops defend bad cops?", International Economic Review, vol. 45, núm. 3, pp. 787-809.

Bourdieu, Pierre, 2002, Razones prácticas. Sobre la teoría de la acción, Barcelona, Anagrama.

Brown, Ben, Wm Reed Benedict y William V. Wilkinson, 2006, “Public Perceptions of the Police in Mexico: a Case Study", Policing: An International Journal of Police Strategies E Management, vol. 29, núm. 1, pp. 158-175.

Consulta Mikofsky 2004-2010, Confianza en las instituciones, en: www.consulta.com. $\mathrm{mx}$

Crawford, Charles y Ronald Burns, 2008, "Police use of force: assessing the impact of time and space", Policing \& Society, vol. 18, núm. 3, pp. 322-335.

Davis, Diane E., 2006, "Undermining the Rule of Law: Democratization and the Dark Side of Police Reform in Mexico", Latin American Politics and Society, vol. 48, núm. 1, pp. 56-86.

Douglas, Mary, 1996, Cómo piensan las instituciones, Madrid, Alianza.

Ford, Robert E., 2003, "Saying One Thing, Meaning Another: The Role of Parables in Police Training", Police Quarterly, vol. 6, núm. 1, pp. 84-110.

Garland, David, 2005, La cultura del control. Crimen y orden social en la sociedad contemporánea, Barcelona, Gedisa.

Goldschmidt, Jona y Anonymous, 2008, "The necessity of dishonesty: police deviance, 'making the case', and the public good", Policing \& Society, vol. 18, núm. 2, pp. 113-135.

King, William R., 2005, “Toward a better understanding of the hierarchical nature of police organizations: Conception and Measurement", Journal of Criminal Justice, vol. 33, núm. 1, 97-109.

Kutnjak Ivkovich, Sanjia y Tara O'Connor Shelley, 2010, “The police code of silence and different paths towards democratic policing", Policing $\mathcal{E}$ Society, vol. 18, núm. 4, pp. 445-473.

Larose, A. P., y S. A. Maddan, 2009, "Reforming La Policía: looking to the Future of Policing in Mexico", Police Practice and Research, vol. 10, núm. 4, pp. 333-348. 
Lomnitz, Claudio (coord.), 2000, Vicios públicos, virtudes privadas: la corrupción en México, México, Porrúa.

López Alvarado, Mauricio, 2007, “Corrupción y control en la organización policial preventiva”, Acta Republicana, núm. 6, pp. 47-56.

Naval, Claire, 2006, Irregularidades, abuso de poder y maltratos en el Distrito Federal. La relación de los agentes policiales y del Ministerio Público con la población, México, Fundar.

Naylor, R. T., 2003, "Towards a General Theory of Profit-Driven Crimes", British Journal of Criminology, vol. 43, núm. 1, pp. 81-101.

Ortega, José Antonio, 2008, El secuestro en México, México, Planeta.

Padgett, Humberto, 2010, Jauría, México, Grijalbo.

Pastor, Daniel R., 2005, "La deriva neopunitivista de organismos y activistas como causa del desprestigio actual de los derechos humanos", Nueva Doctrina Penal, núm. 1, pp. 73-114.

Phillips, Tim y Philip Smith, 2000, "Police Violence occasioning Citizen Complaint", British Journal of Criminology, vol. 40, núm. 3, pp. 480-496.

Ruiz Torres, Miquel À. y Elena Azaola, 2012, “La experiencia en prisión de ex policías sentenciados por secuestro en México", International Journal of Latin American Studies, vol. 2, núm. 2, pp. 139-169.

Saín, Marcelo, 2008, El Leviatán azul: policía y política en la Argentina, Buenos Aires, Siglo XXI Editores.

Scherer García, Julio, 2009, Secuestrados, México, Grijalbo.

Silva, Carlos, 2003, "Abuso policial en la ciudad de México", Conferencia Reforming the Administration of Justice in Mexico, San Diego, Center for US-Mexican Studies.

Skolnick, Jerome H., 2002, "Corruption and the Blue Code of Silence", Police Practice and Research, vol. 3, núm. 1, pp. 7-19.

Stanley, Ruth, 2004, "Everyday forms of illegal coercion: Explaining abuse of police powers in Argentina", Journal of Third World Studies, vol. 21, núm. 2, pp. 85-105. 
Suárez de Garay, María Eugenia, 2005, “Armados, enrejados, desconfiados... Tres breves lecturas sobre la cultura policial mexicana", Política y Sociedad, vol. 42, núm. 3, pp. 87-102.

Trostle, Lawrence, 2005, "Police solidarity and tolerance for police misbehaviour, revisited", Psychological Reports, vol. 96, núm. 1, pp. 26-28.

Westmarland, Louise, 2005, "Police ethics and integrity: Breaking the blue code of silence", Policing E Society, vol. 15, núm. 2, pp. 145-165.

Wilson, Richard W., 1992, Compliance ideologies. Rethinking political culture, Cambridge University Press.

Recibido el 27 de febrero de 2013

Aceptado el 11 de marzo de 2014 